\title{
Mapping and assessment of urban heat island effects in the city of Sofia, Bulgaria through integrated application of remote sensing, unmanned aerial systems (UAS) and GIS
}

Stelian Dimitrov, Anton Popov, Martin lliev

Stelian Dimitrov, Anton Popov, Martin Iliev, "Mapping and assessment of urban heat island effects in the city of Sofia, Bulgaria through integrated application of remote sensing, unmanned aerial systems (UAS) and GIS," Proc. SPIE 11524, Eighth International Conference on Remote Sensing and Geoinformation of the Environment (RSCy2020), 115241A (26 August 2020); doi: $10.1117 / 12.2571967$ 


\title{
MAPPING AND ASSESSMENT OF URBAN HEAT ISLAND EFFECTS IN CITY OF SOFIA (BULGARIA) THROUGH INTEGRATED APPLICATION OF REMOTE SENSING, UNMANNED AERIAL SYSTEMS(UAS) AND GIS
}

\author{
Stelian Dimitrov*a, Anton Popov ${ }^{\mathrm{a}}$, Martin Iliev ${ }^{\mathrm{a}}$ \\ aSofia University “St. Kliment Ohridski, 15 Tsar Osvoboditel Bd, Sofia , Bulgaria 1504;
}

\begin{abstract}
This article aims to present the developed, adapted and applied methodology for the study, mapping, and evaluation of the effect and intensity of the urban heat island(UHI) within the urban space of the city of Sofia, while assessing its potential impact on the structure of the city and the prospects for its development and structure. For this purpose, a combination of GIS-based spatial analysis techniques is used, based both on the application of traditional satellite data sources and on the use of state-of-the-art unmanned aerial vehicle systems (UAVs), delivering highresolution information. The results obtained from the study are adapted towards their use for the purpose of supporting urban planning processes in the city and could greatly assist in the establishment of more adequate models of spatial planning in the urban area of Sofia, in the context of global climate change and the expected intensification of the UHI effects in the near future.
\end{abstract}

Keywords: Urban heat island (UHI), Remote sensing, Unmanned aerial systems (UAS), GIS and geoinformation technologies

\section{INTRODUCTION}

The urban heat island (UHI) affects a substantial part of the world's urban population, its health status and lifestyle [1]. It is a direct consequence and results from the processes of intensive urbanization, which are the major factor for changing the geographical structure of the territory, resulting in a deep and comprehensive transformation of natural landscapes and ecosystems into artificial habitats, with a substantial predominance of artificial, impervious surfaces over natural ones. On the other hand, UHI is a local geospatial phenomenon, with complex dynamics and spatial distribution in urban territories, and its parametrization is essential for the effective planning and management of urban areas [2,3,4].

Unlike standard climate studies, which rely mainly on stationary, standardized and calibrated monitoring networks, providing data over a long period of time, studies on the UHI can vary considerably as far as spatial dimensions are concerned (from several tens of meters to several tens kilometers) and the time intervals, used to observe and investigate these phenomena (from several hours to years) [5]. This, in turn, implies the use of different approaches to collect data, especially based on contemporary geospatial tools and applications. These tools are supporting the research processes, offering a rapid (operative) collection of geospatial data on surface temperature and the temperature of the ground contact air layer, for compact, diverse and complex territories, such as urban areas. This trend is also including the intensive application of Unmanned aerial systems (UAS), that has been increasingly used recently as platforms for the operational collection of geospatial data of different genesis and characteristics $[6,7]$.

The purpose of this study is to present the developed and used methodology for the study of UHI effects and their major spatial characteristics, within the territory of Bulgarian capital- the city of Sofia. The research is based on the integrated use of various geospatial technologies, including the capabilities of the UAS. The achieved results have great potential, In terms of spatial resolution and quality characteristics, to integrate the UHI problematics into the planning and management processes of the urban area of Sofia, where this is currently not considered.

*stelian@gea.uni-sofia.bg; phone +359878417859; www.uni-sofia.bg

8th International Conference on Remote Sensing and Geoinformation of the Environment, edited by

K. Themistocleous, et al. Proc. of SPIE Vol. 11524, 115241N · @ The Authors. Published under a

Creative Commons Attribution CC-BY 3.0 License · doi: 10.1117/12.2571967 


\section{MATERIALS AND METHODS}

\subsection{Study area}

The present study is focused on the urbanized area of Sofia - the capital of Bulgaria. The city is located in the largest valley in Bulgaria - Sofia (about 1200 sq. $\mathrm{Km}$ ) at 550 meters above sea level. The relief of the valley floor is flat, with a slight slope up to the north. To the north, it is surrounded by the Balkan Mountains and to the south- by the Vitosha Mountain. The climate is temperate continental with clearly distinguished four seasons. According to the Sofia Station, which operates from 1881 to the present, the average annual temperature is $10.3{ }^{\circ} \mathrm{C}$, and the average annual rainfall is $612 \mathrm{~mm}$, with a maximum in May-June. The average temperature of the coldest month is $-1.7{ }^{\circ} \mathrm{C}$ and the warmest month is $21.2{ }^{\circ} \mathrm{C}$. The measured absolute minimum air temperature is $-27.5^{\circ} \mathrm{C}$ and the absolute maximum temperature is $37.4{ }^{\circ} \mathrm{C}$. Sofia's urban area is a complex combination of different functional zones (administrative, residential, industrial, transport, commercial, parks, etc.), that have been developed at different times, over a very long period of time.

\subsection{Methodological framework}

The present study is based on an integrated scheme of application of different methods for collecting, analyzing and processing geospatial data and generating geo-referenced information, which allows characterizing, mapping and evaluating the basic parameters of the formed surface urban heat island (SUHI) within the urbanized area of Sofia. In order to achieve this, the following key research activities have been undertaken, organized in 4 logically related research phases:

1) Climatic zoning on the territory of the city, using the Local Climate zoning (LCZ) concept, which is based on the combined use of remote sensing input data (mainly orthophoto maps from 2017), as well as up-to-date cadastral information.

2) A general mapping of the SUHI phenomenon, based on remote sensing data from the Landsat satellite platform, identifying the general characteristics of the different types of land cover and their "contribution" to the overall spatial configuration of the phenomenon within the city and its surroundings;

3) Conducting a sample stratified study of SUHI magnitude, using a UAS platform, with a self-calibrating thermal sensor.

4) GIS analysis and interpretation of the spatial characteristics of the intensity of the phenomenon within the city, (trough geostatistical tools and methods of spatial modeling).

\subsection{Local climate zones $(\mathrm{LCZ})$}

For the purposes of the study, a classification scheme for the LCZ for the territory of Sofia was developed, by using the fundamentals of the proposed and widely applied LCZ scheme, suggested by Oke and Stewart [8]. It has been successfully used in various as structure and genesis urban areas in recent years and has gradually established itself as a leading classification scheme for this type of research. What is specific in this case, is that the scheme is implemented in the form of a structured GRID, formed by cells of uniform size and geometry, which cover the territory of the urban space. This geospatial structuring approach allows a better adaptation of the spatial data, resulting from LCZ, for the purposes of stratified sampling and subsequent geostatistical processing. Each cell is $250 \times 250 \mathrm{~m}$ in size, covering an area of 6.25 ha, divided into 13 types (classes) of zones (Fig.1). 


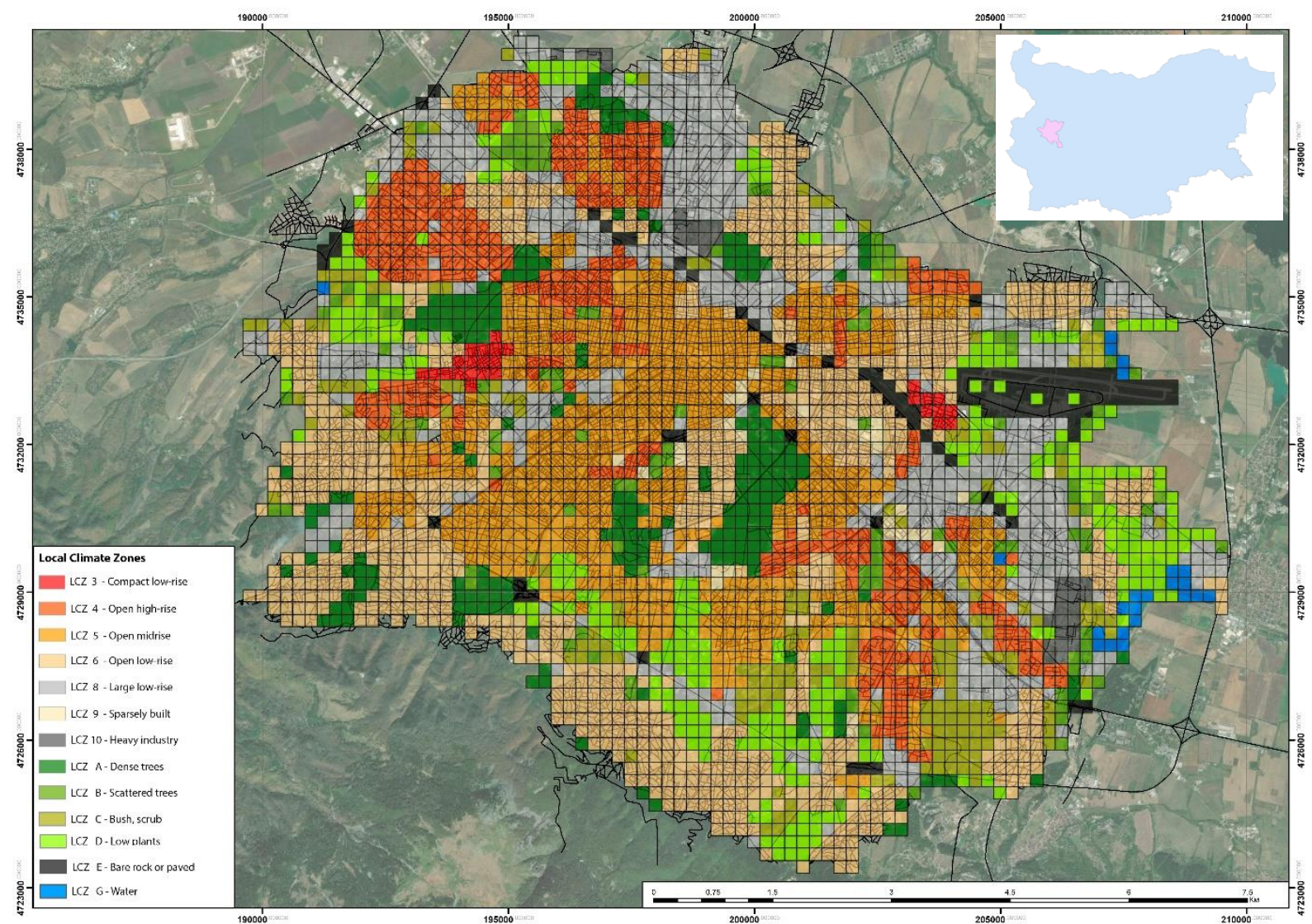

Figure 1. LCZ in Sofia as grid 250x250m

The developed LCZ classification for the city of Sofia does not identify three types of zones from the original scheme, proposed by Oke and Stewart: LCZ 1. Compact high-rise building, LCZ 2. Compact medium-high build-up and LCZ 7. Unstable low build-up. The reason for this missing is either the three types of LCZ are too small and fragmented, or because the source data for their identification (orthophoto plans and cadastral data) is not with the appropriate resolution for their spatial recognition. The share distribution for each type of LCZ is presented in Table 1.

Table 1. Number of cells per LCZ, area and relative share of identified LCZ

\begin{tabular}{|l|l|l|l|}
\hline LCZ & $\begin{array}{c}\text { Number of } \\
\text { cells }\end{array}$ & \multicolumn{1}{|c|}{$\begin{array}{c}\text { Area } \\
\text { /ha/ }\end{array}$} & \multicolumn{1}{|c|}{$\begin{array}{c}\text { Area } \\
\text { /\%/ }\end{array}$} \\
\hline LCZ_3 & 26 & 162.5 & 0.8 \\
\hline LCZ_4 & 346 & 2162.5 & 10.5 \\
\hline LCZ_5 & 636 & 3975.0 & 19.3 \\
\hline LCZ_6 & 723 & 4518.8 & 21.9 \\
\hline LCZ_8 & 547 & 3418.8 & 16.6 \\
\hline LCZ_9 & 34 & 212.5 & 1.0 \\
\hline LCZ_10 & 34 & 212.5 & 1.0 \\
\hline LCZ_A & 216 & 1350.0 & 6.5 \\
\hline LCZ_B & 117 & 731.3 & 3.5 \\
\hline
\end{tabular}




\begin{tabular}{|l|l|l|l|} 
LCZ_C & 194 & 1212.5 & 5.9 \\
\hline LCZ_D & 298 & 1862.5 & 9.0 \\
\hline LCZ_E & 105 & 656.3 & 3.2 \\
\hline LCZ_G & 23 & 143.8 & 0.7 \\
\hline Total & $\mathbf{3 2 9 9}$ & $\mathbf{2 0 6 1 8 . 8}$ & $\mathbf{1 0 0}$ \\
\hline
\end{tabular}

\subsection{Remote sensing techniques and methods}

In this study, two sets of remote sensing data are used: a) remote sensing data from satellite platforms (in this case, Landsat) and b) collected data through the use of Unmanned aerial system (UAS) platform.

\subsubsection{Satellite remote sensing data}

Thermal (thermographic) satellite images have been used to provide a general mapping of the SUHI effect, providing a dense network of time-synchronized temperature data on the earth, including urban areas [9]. In this case, the thermal channel (TIRS) of the Landsat 8 platform is used, where the temperature of the earth's surface was derived by a calculation algorithm based on the following channels: 10 thermal, 4 RED, and 5 NIR [10].

The result of the above calculation is a digital geospatial data representation of the urbanized teritory of Sofia and the surrounding area, delivering information about the surface temperature at the time of image capture, as well as about the nature of the landcover (in terms of vegetation distribution and impervious areas).

The main problem and significant disadvantages of the applied methodology are related to the restrictions that objectively exist regarding the period during the actual satellite "snapshots" are taken. In this case, the images from Landsat 8 platform are taken at noon local time, when the earth's surface has been overheated. This is resulting in serious distortions of the parametrization and specifications of the UHI effects within the study area. Additionally, that problem leads to other limitations, including the inability to the intensity of UHI to be calculated correctly.

Regardless of this disadvantage of the Landsat satellite data for the present study, the results clearly show that urbanized territories are characterized with significantly higher surface temperatures than areas dominated by natural landscapes. For example, in the created geospatial model of the surface temperature based on the noon image from 12.08.2019 (Fig.2), we can see the significant heterogeneity of the temperature of the surface of Sofia and the adjacent territories, with a temperature variation of more than $26^{\circ} \mathrm{C}$ between the most and the least heated surfaces. 


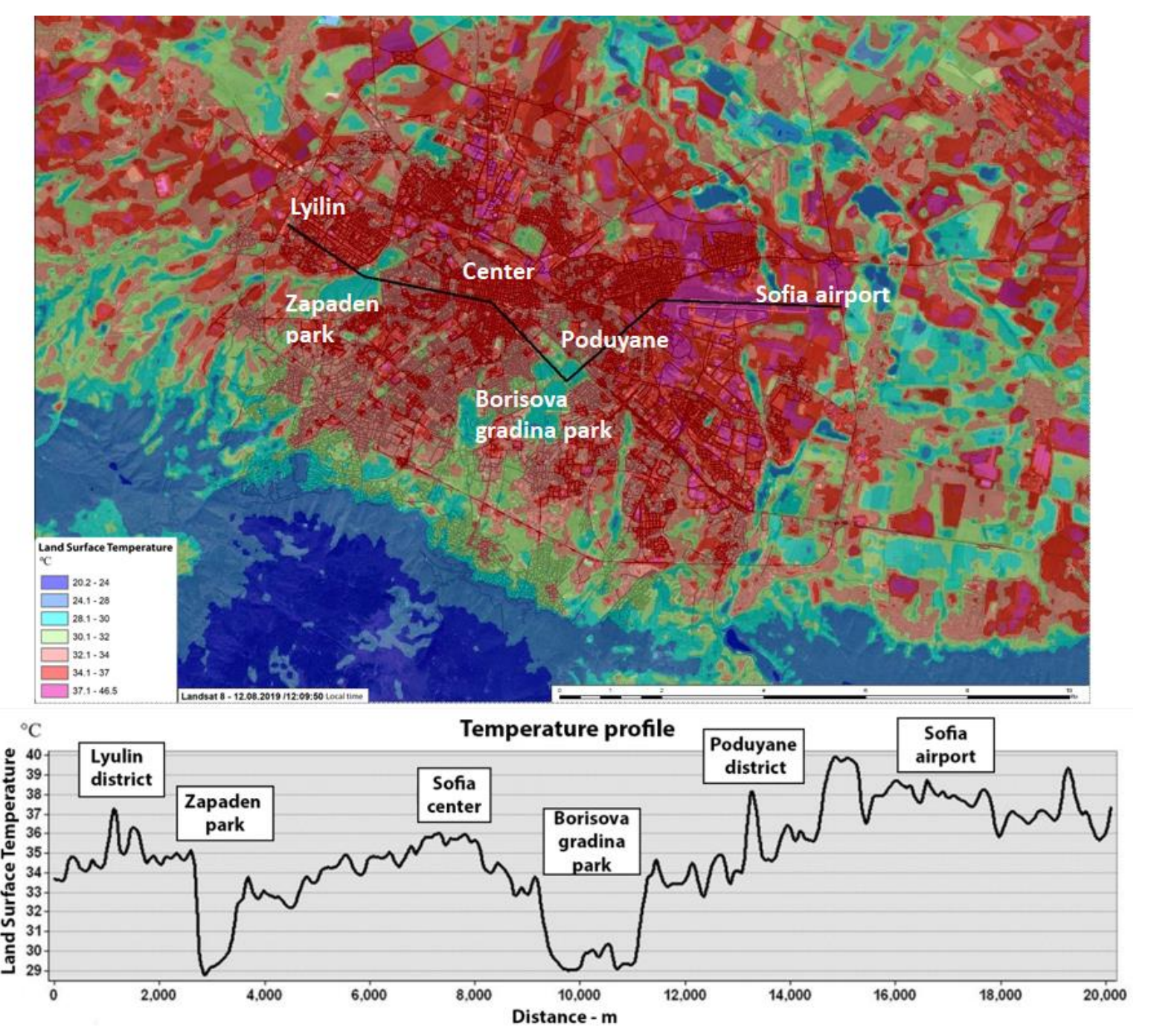

Figure 2. Temperature profile across Sofia on Landsat thermal channel map from 12.08.2019 (noon)

\subsubsection{UAS remote sensing data}

To compensate the shortcomings of the satellite data, in the present research has been used UAS system with installed Thermal Infrared (TIR) sensor. In this case, was used the Albris platform of the Swiss company Sensefly, which is an inspection $\mathrm{V}$-shaped quadcopter with 5 sensors and 3 camcorders, allowing 3 types of imaging with image detail below $1 \mathrm{~mm}$, depending on the subject of study. The system is equipped with a TIR camera with parameters $80 \times 60$ pixels, with a 50-degree angle and a fixed measuring point, positioned on a 3-axis head (gimble). The unmanned aerial system enables remote capture of thermal images and video with dynamically adaptable scale in real time (Fig. 3). 

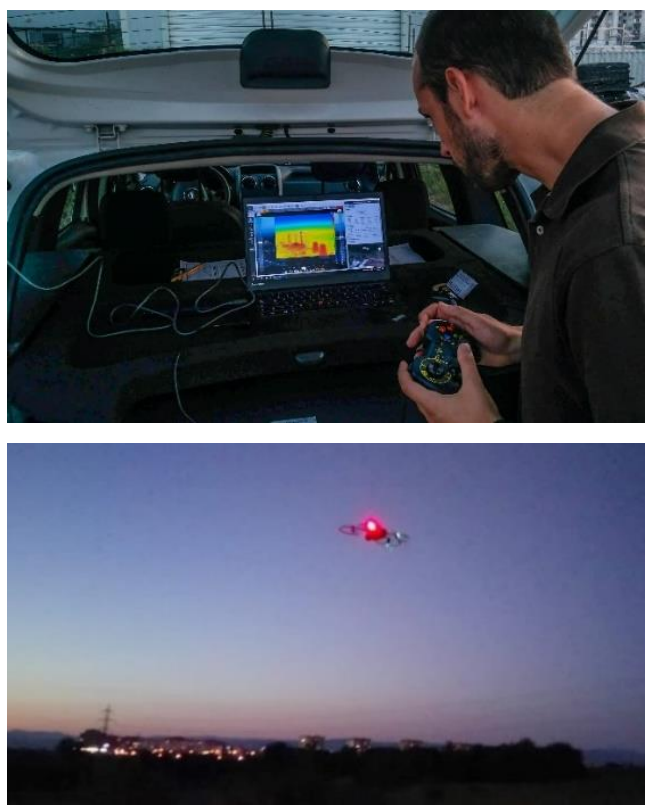
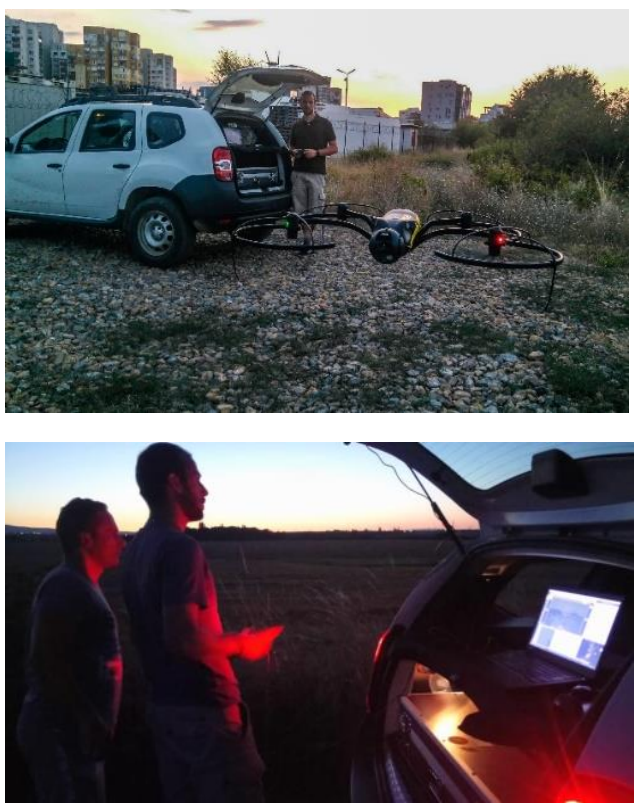

Figure 3. Terrain sampling data collection through UAS platform

Due to the constraints of the used UAS platform for data collection, related to its objective limitations in terms of operational time and spatial cover, for the present study, has been developed and applied a stratified sampling scheme (STR) approach. Regarding this, for each LCZ has been determinated a specific number of cells to be observed through i-situ observations, through the use of the UAS platform with TIR sensor on it. The total number of observed grid-cells is 74 , which number is determined by the method of the non-return selection[11,12,13]. The most appropriate study period of the year is August, which is the month with the highest average temperature of the earth's surface, which is a fundamental prerequisite for the most visible signs of the UHI phenomenon. Its effect is most clearly observed during the early evening hours, immediately after the active sunshine [14], with relative windiness and cloudless sky. In this part of the day, there is the best opportunity to maximize the potential for precise identification of micro and local climatic differences between urbanized territories and their response to UHI. Regarding this, the time interval between 8:00h, and 10:00 PM was selected for thermal imaging observations for the predefined grid cells (Fig. 4). 

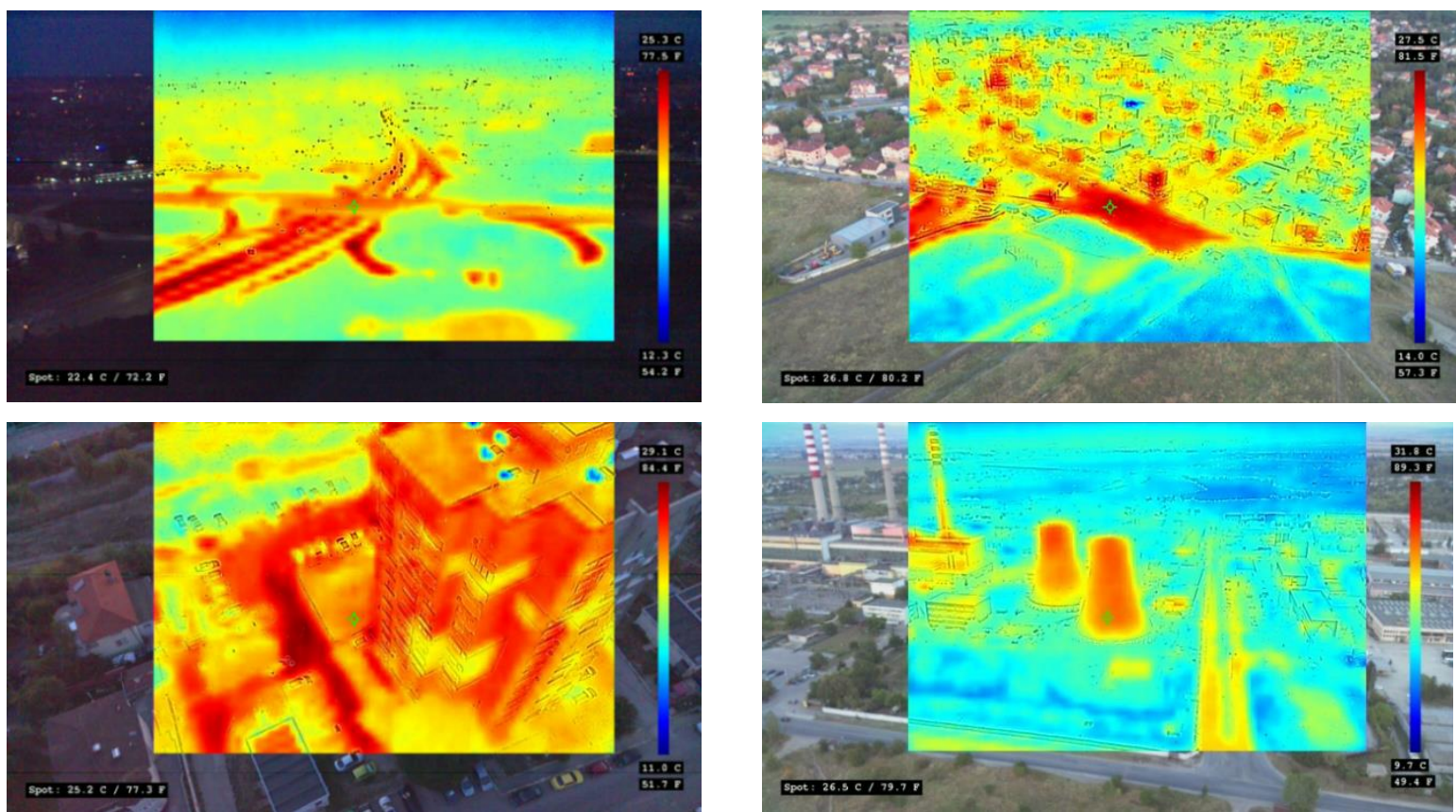

Figure 4. Thermal images examples from UAS platform

\subsection{Spatial interpretation and analysis of field research data. Determination of SUHI intensity}

The results in-situ UAS based thermal surveys are used to construct linear regression dependencies through the least-squares method, between the areas of the main land-use types (as an independent quantity) and the average measured temperatures by land-use types (as a dependent value). The general conclusions confirm the hypothesis, that the greater the proportion of green space, the lower are the measured temperature values, and vice versa - the higher the proportion of built-up and impervious areas, the higher are the surface temperatures:

- With an increase in the proportion of green areas in the LCP there is a clear tendency for a decrease in the surface temperature between 8-10 PM (fig.5) 


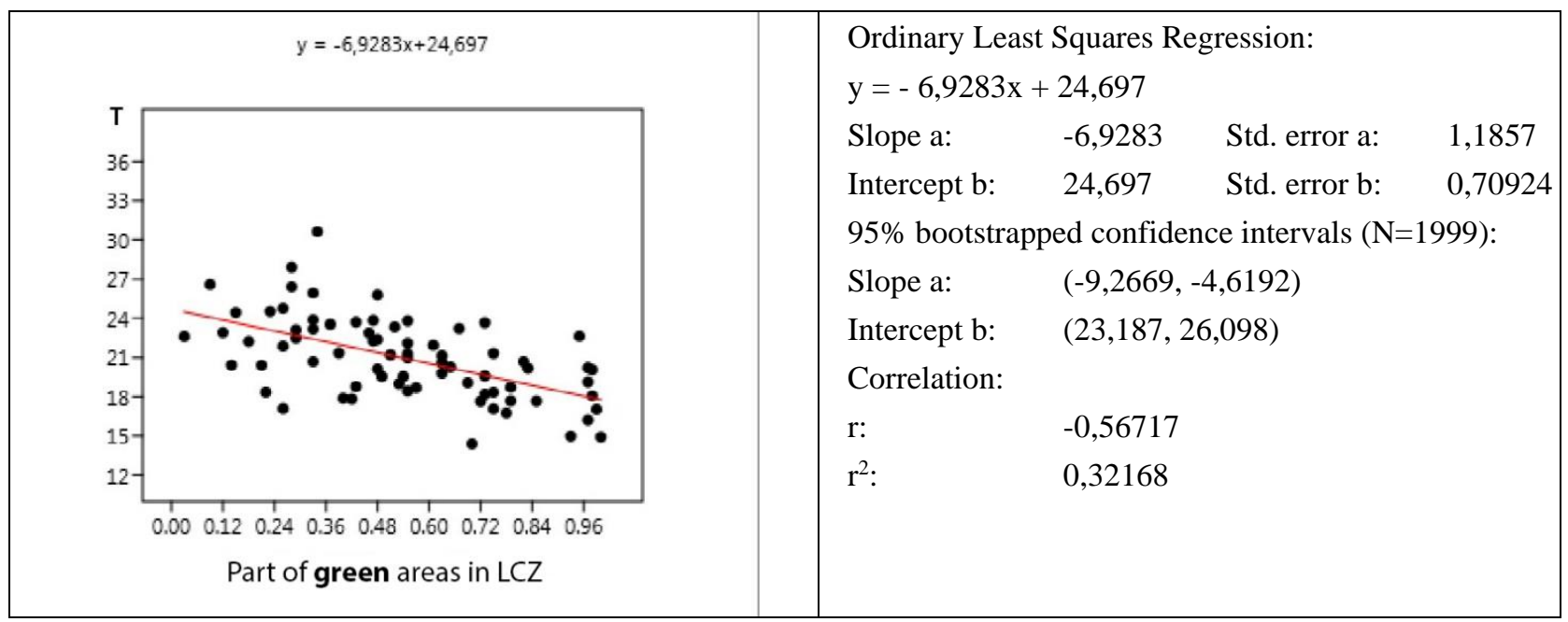

Figure 5. Linear regression dependence - green areas

- With the increase the share of impervious areas there is a strong tendency for the surface temperature to increase (between 8 and 10PM)(Fig.6)

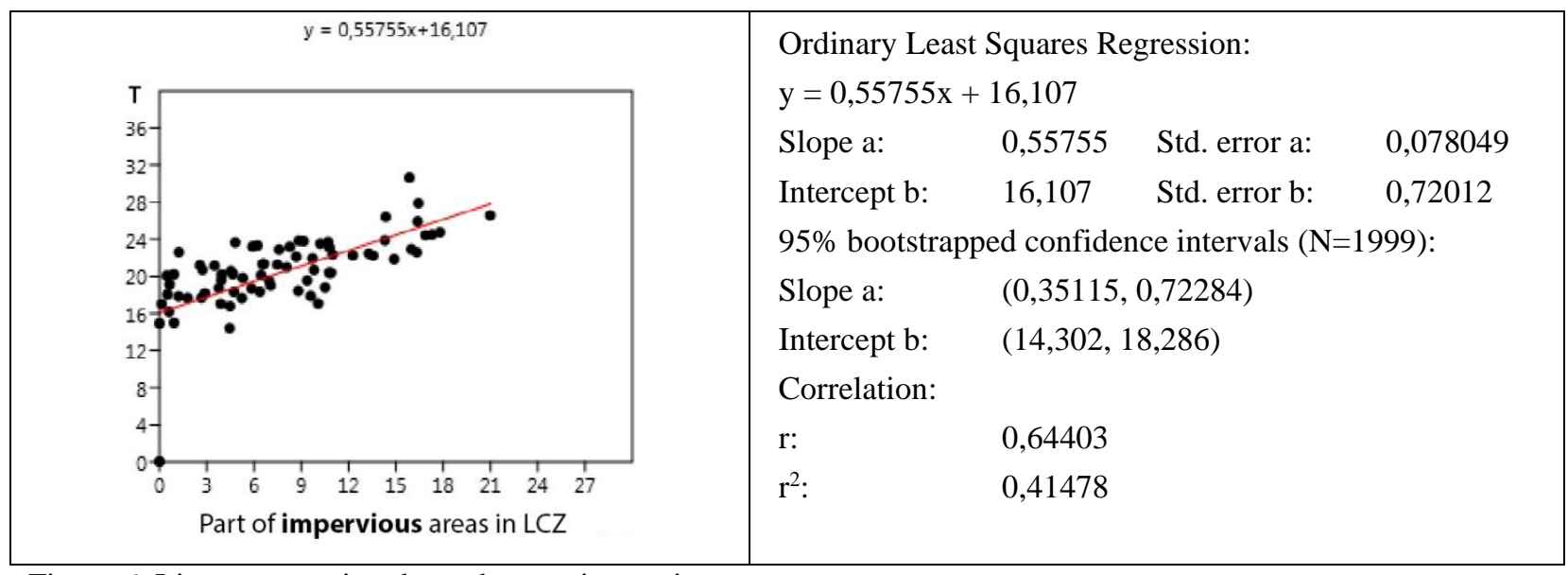

Figure 6. Linear regression dependence - impervious areas

- With the increase of the share of buildings (density of buildings) in LCZ, there is a pronounced tendency to increase the surface temperature (between 8 and 10 PM)(Fig.7) 


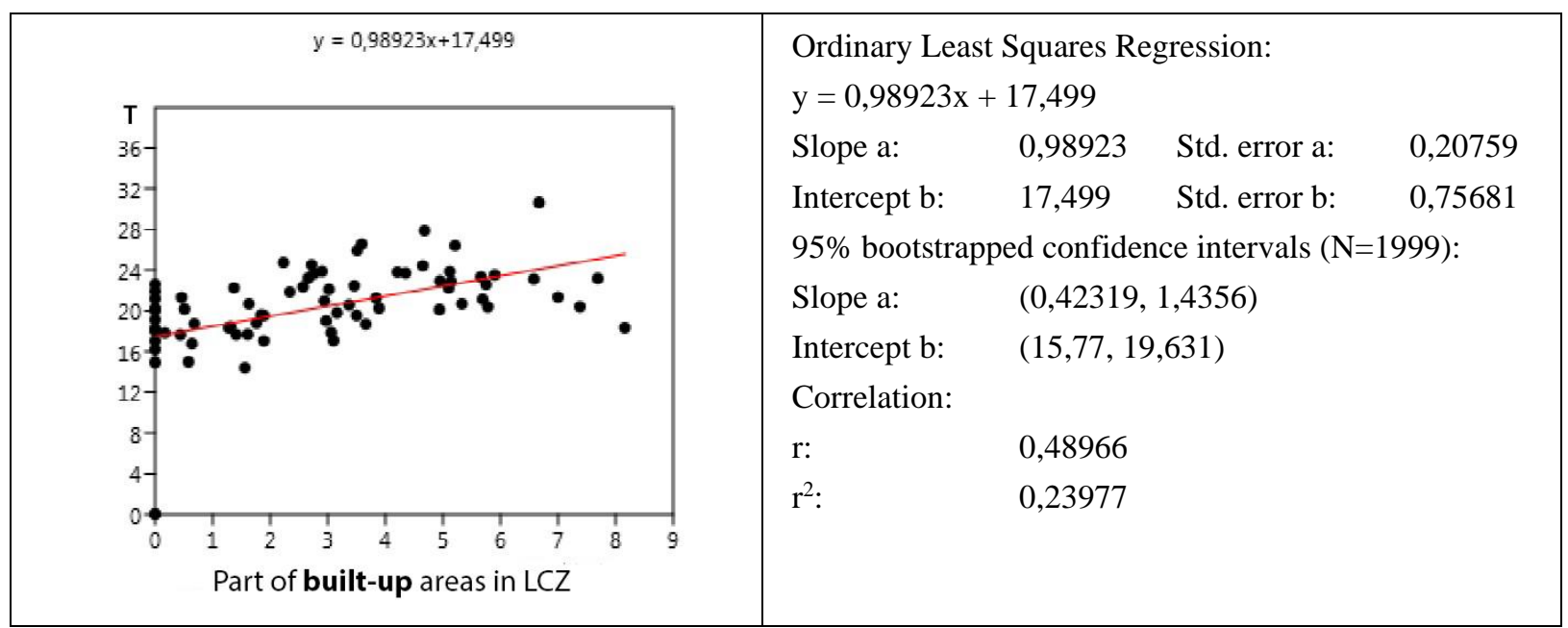

Figure 7. Linear regression dependence -build-up areas

Using the created regression dependencies, and the spatial distribution of the measurements made by UAS, a geostatistical model of the spatial distribution of the surface temperature within the city of Sofia was created. For this purpose, an approach for deterministic local interpolation is applied whereby the predicted values are generated within local groups of adjacent points based on the network of measured values and their locations via UAS.

The result of spatial interpolation clearly shows that within the urban space in Sofia a poly-structural (polycentric) urban heat island has been formed (Fig.8).

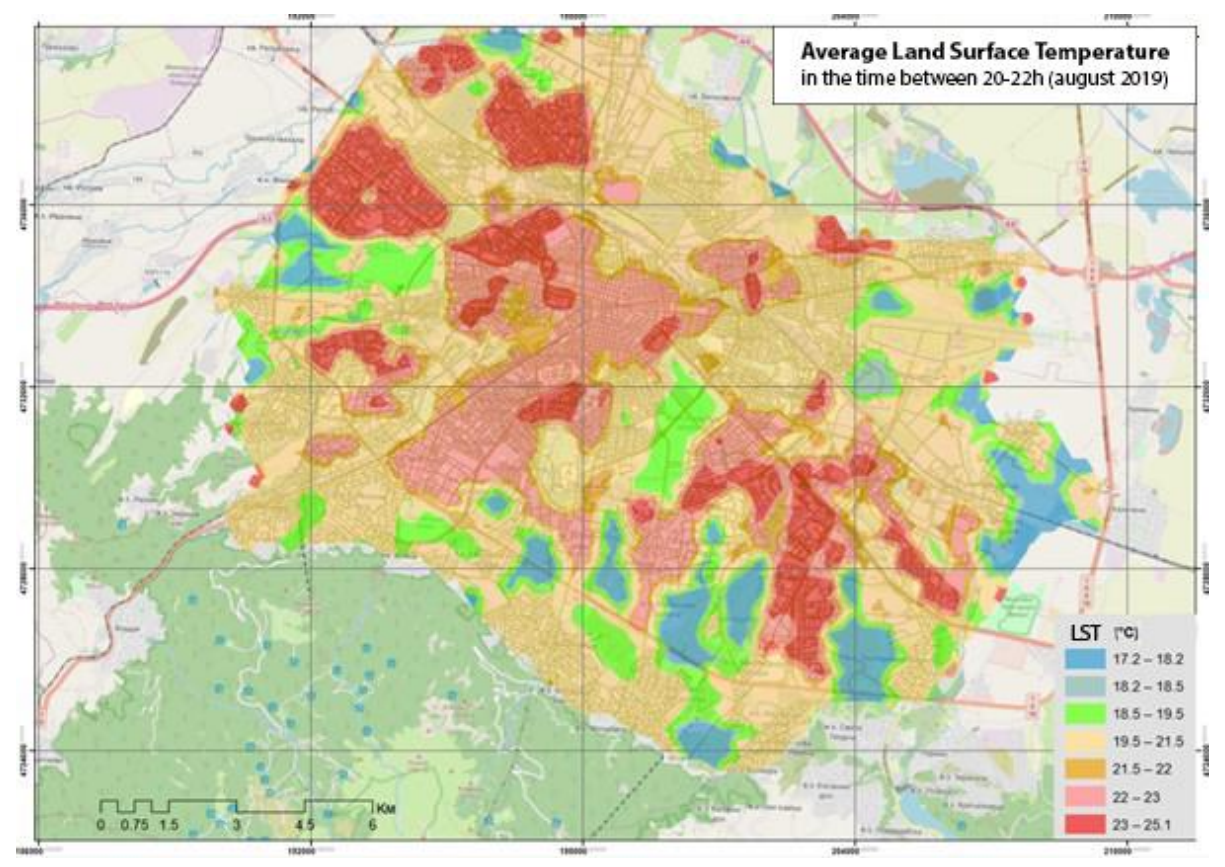

Figure 8. Map of spatial distribution of calculated and interpolated land surface temperatures (LSTs) in Sofia between 8:00 and 10:00 PM

The great diversity of the territories involved in the different LCZs, as well as the high spatial variability of their spatial structure, determines to a large extent the complex and poly-structural nature of the UHI phenomenon. For example, only one section of 1000 square meters exhibits significant temperature contrasts. The figure below shows a fragment of a field measurement of the surface temperature in 22 hours, carried out in the area of a large hypermarket in Sofia. The image clearly shows that within this confined space, extremely large differences in surface temperature are 
observed - in the grassland it is within $12.9-13.1^{\circ} \mathrm{C}$, in the parking places made of concrete rosette panels it is $17.1^{\circ} \mathrm{C}$ respectively and on the asphalt road $23.6{ }^{\circ} \mathrm{C}$ (Fig. 9).

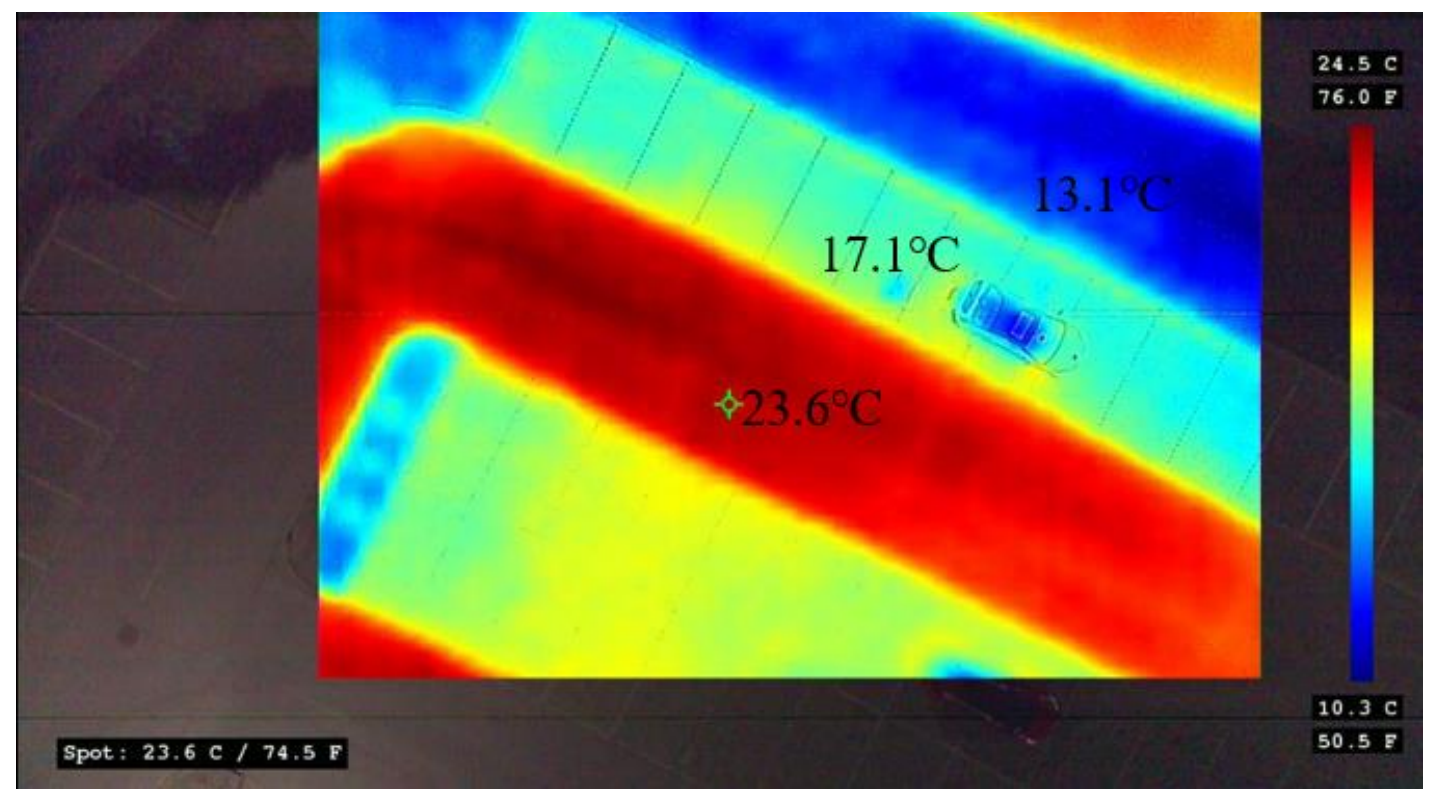

Figure 9. Thermal image example of the differences between land surface temperatures of different land cover types (hypermarket "HIT" in Lyulin district, Sofia ( 9:30 PM, 07.08.2019)

These temperature differences are characterizing the complexity of the UHI and represent one of its most important of its core parameters - the intensity (magnitude) of the phenomenon. The intensity of the LST for each LCZ objectively characterizes the power of manifestation of the LST in a spatial aspect. The intensity is calculated as follows [15]:

\section{$\triangle \mathrm{TLCZ} \mathrm{X}-\mathrm{Y}$,}

where $\Delta T$ is the maximum difference from the expression LCZ X - Y, in which $\mathrm{X}=$ the temperature of the given $\mathrm{LCZ}$, and Y- the temperature of the other LCZs for comparison. The data on the temperature differences between all LCZs in Sofia are presented in Table. 2.

Table 2. Temperature differences between LCZ, necessary for calculation and mapping of SUHI magnitude

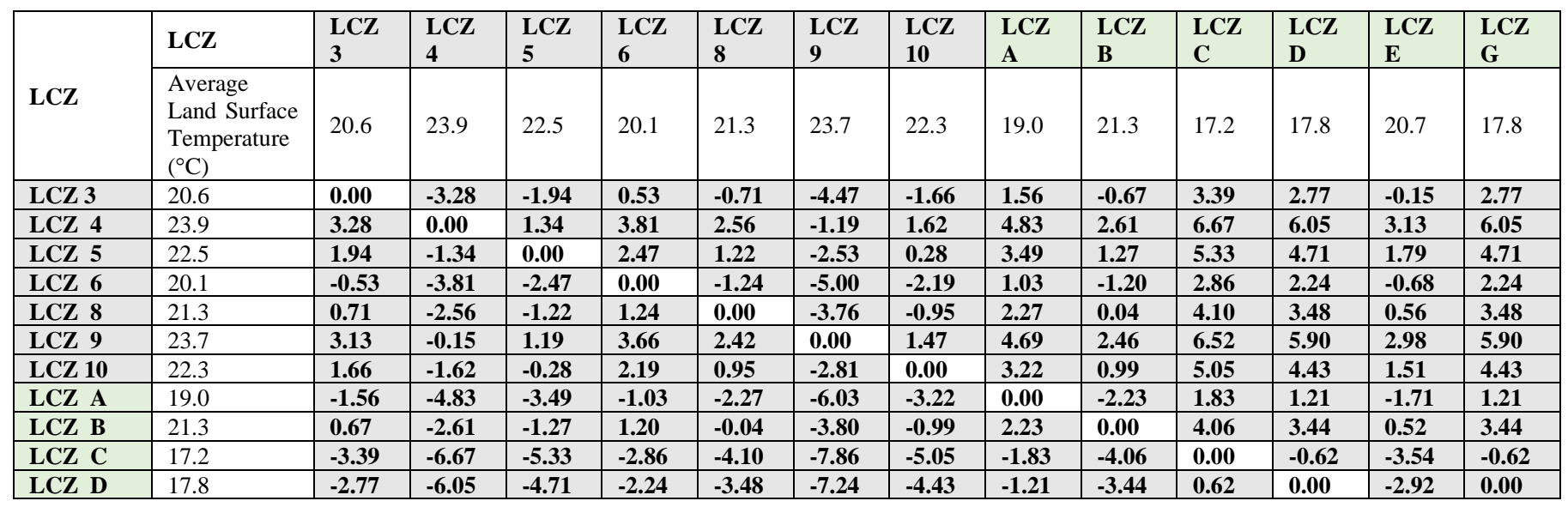




\begin{tabular}{|c|c|c|c|c|c|c|c|c|c|c|c|c|c|c|}
\hline LCZ E & 20.7 & 0.15 & -3.13 & -1.79 & 0.68 & -0.56 & -4.32 & -1.51 & 1.71 & -0.52 & 3.54 & 2.92 & 0.00 & 2.92 \\
\hline $\mathrm{LCZ} \mathrm{G}$ & 17.8 & -2.77 & -6.05 & -4.71 & -2.24 & -3.48 & -7.24 & -4.43 & -1.21 & -3.44 & 0.62 & 0.00 & -2.92 & 0.00 \\
\hline
\end{tabular}

Based on the data from the matrix in the table, a statistical surface was created using a local polynomial interpolation, representing in a continuous form the UHI magnitude in the urban space of Sofia (Fig. 10).

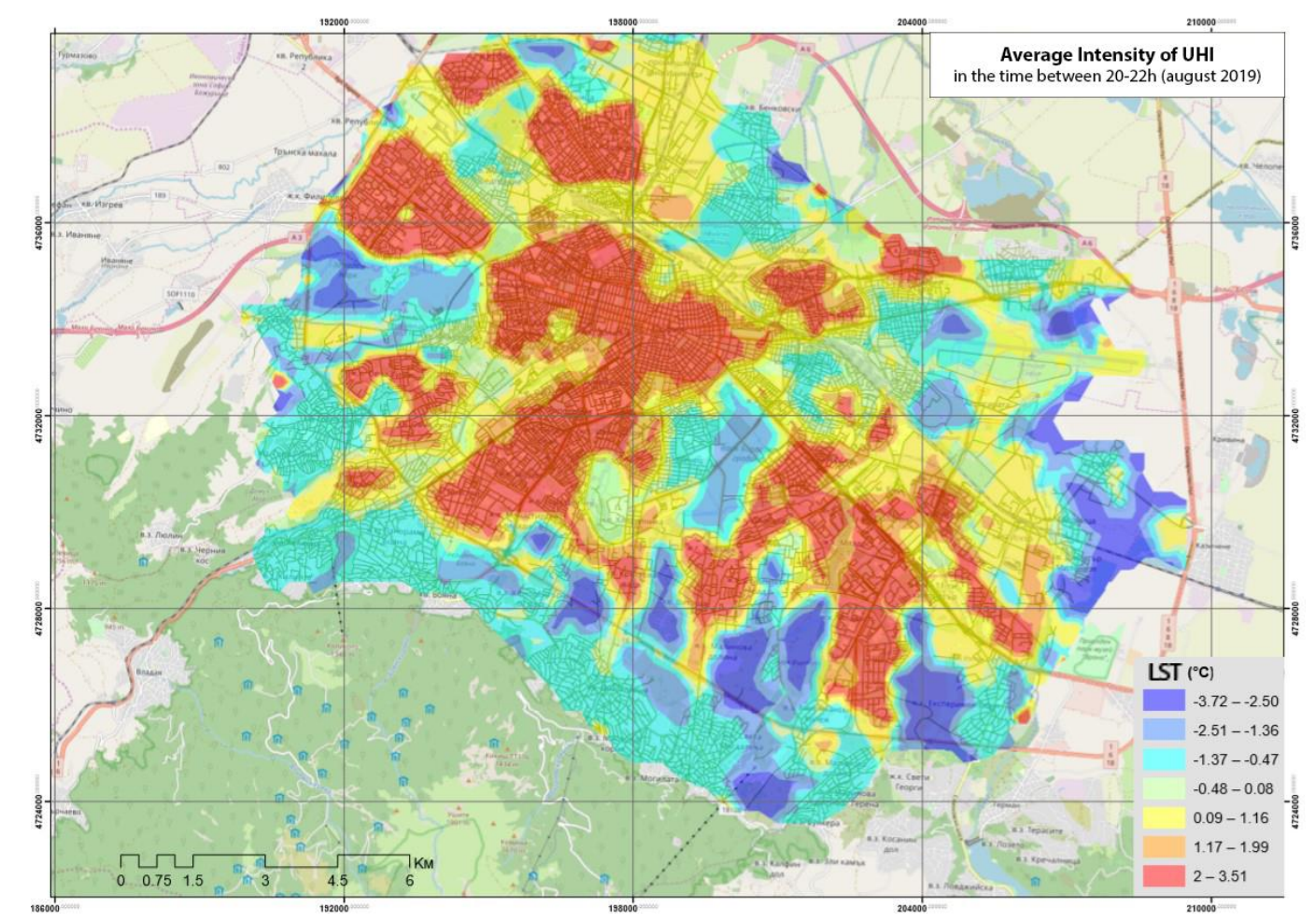

Figure 10. Map of average magnitude of SUHI in Sofia for August 2019 г. (8:00-10:00 PM)

\section{DISCUSSION}

The results of the study of the effect of SUHI within Sofia's urban area through the integrated application of geoinformation technological and analytical solutions (including UAS), show that the application of this approach in the collection of geospatial data on the effect of SUHIs, their analysis, and interpretation. There are a number of significant advantages. These advantages are associated with the low cost of the study and the high degree of responsiveness and flexibility of application of the approach. In addition, the application of UAS makes it possible to obtain extremely detailed information about small-sized territories, but with a high degree of variability in the structure of land cover and land-use patterns, which is a feature of modern urban areas. All this leads to the conclusion that this approach has the considerable capacity and potential for practical application, including for the purposes of planning and managing urban systems.

However, some significant constraints should be taken into account when applying the approach, which is mainly explicitly related to the application of UAS as a platform for the collection of empirical data characterizing the PIC phenomenon. These include the limitations associated with both the limited spatial scope and operational capacity these systems have and the need to provide more reliable and accurate sensors for measuring surface temperature. On the other hand, these technologies are evolving extremely rapidly, and it can be safely concluded that they have the potential to revolutionize the approaches and methods of collecting local geospatial information, as happened with GIS several decades ago.. 


\section{AKNOWLEDGMENTS}

This work has been carried out in the framework of the National Science Program "Environmental Protection and Reduction of Risks of Adverse Events and Natural Disasters", approved by the Resolution of the Council of Ministers No 577/17.08.2018 and supported by the Ministry of Education and Science (MES) of Bulgaria(Agreement No Д01$322 / 18.12 .2019)$.

\section{REFERENCES}

[1] Mohajerani, A. Bakaric, J. and Jeffrey-Bailey, T. 2017, 'The urban heat island effect, its causes, and mitigation, with reference to the thermal properties of asphalt concrete', Journal of Environmental Management, Elsevier, United Kingdom, vol. 197, pp. 522-538 ISSN: 0301-4797.

[2] Soux, A., Voogt, J. \& Oke, T.R., 2004. A model to calculate what a remote sensor "sees" of an urban surface. Boundary-Layer Meteorology, 111(1), pp. 109-132

[3] Zhan, W. et al., 2013. Disaggregation of remotely sensed land surface temperature: Literature survey, taxonomy, issues, and caveats. Remote Sensing of Environment, 131, pp. 119-139. DOI: 10.1016/j.rse.2012.12.014Myhrvold, N., "Confessions of a cybershaman," Slate, 12 June 1997, <http://www.slate.com/CriticalMass/97-0612/CriticalMass.asp> (19 October 1997). www.optics4yurresearch.com/7752.html

[4] Bonafoni, S., Baldinelli, G., \& Verducci, P.,Sustainable strategies for smart cities: analysis of the towndevelopment effect on surfaceurban heat island through remote sensing methodologies.Sustainable Cities and Societyhttp://dx.doi.org/10.1016/j.scs.2016.11.005

[5] Stewart, I. D., 2011, Redefining the urban heat island (T). Electronic Theses and Dissertations (ETDs) $2008+$. University of British Columbia. Retrieved November 14, 2019, from: https://open.library.ubc.ca/collections/ubctheses/24/items/1.0072360

[6] Watts, A.C.; Ambrosia, V.G.; Hinkley, E.A. Unmanned Aircraft Systems in Remote Sensing and Scientific Research: Classification and Considerations of Use. Remote Sens. 2012, 4, 1671-1692.

[7] Dimitrov, S., Georgiev G., Georgieva M., Gluschkova M., Chepisheva V., Mirchev P. and Zhiyanski M., 2018 "Integrated assessment of urban green infrastructure condition in Karlovo urban area by in-situ observations and remote sensing", One Ecosystem, 3, e21610. https://doi.org/10.3897/oneeco.3.e21610

[8] Oke TR, Stewart I. Local climate zones for urban temperature studies. Bull. American Meteorological Society. 2012;93:1879-1900

[9] Steininger, M.K., 1996. Tropical secondary forest regrowth in the Amazon: age, area and change estimation withThematic Mapper data. International Journal of Remote Sensing, 17(1), pp. 9-27. DOI: $10.1080 / 01431169608948984$

[10] Avdan, U., Jovanovska, G., 2016. Algorithm for automated mapping of land surface temperature using LANDSAT 8 satellite data. J. Sens. 2016, 1-8.

[11] Cochran, W. G., 1977, Sampling Techniques. 3rd Edition, John Wiley \& Sons, New York.

[12] Lehtonen, R. and Pahkinen, E. J., 1996, Practical Methods for Design and Analysis of Complex Surveys. Revised Edition, November 1996, Statistics in Practice, John Wiley \& Sons, Chichester.

[13] Stehman, S. V., 2000, Practical Implications of Design-Based Sampling Inference for Thematic Map Accuracy Assessment. Remote Sens. Environ. 72, 35-45.

[14] Oke T, Stewart I. Thermal Differentiation of Local Climate Zones Using Temperature Observations from Urban and Rural Field Sites; 2010. Accessed 22 March 2014. Available:https://ams.confex.com/ams/pdfp apers/173127.pdf

[15] Oke TR. Initial Guidance to obtain representative meteorological observations at urban sites. World Meteorological Organization, Instruments and Observing Methods, IOM Report No. 81, WMO/TDNo.1250; 2006 